\title{
OPEN Cutaneous T-cell lymphoma in erythrodermic cases may be suspected on the basis of scalp examination with dermoscopy
}

\author{
Adriana Rakowska ${ }^{1 凶}$, Magdalena Jasińska ${ }^{1}$, Mariusz Sikora ${ }^{1}$, Joanna Czuwara ${ }^{1}$, \\ Patrycja Gajda-Mróz ${ }^{1}$, Olga Warszawik-Hendzel ${ }^{1}$, Małgorzata Kwiatkowska ${ }^{2}$, \\ Anna Waśkiel-Burnat ${ }^{1}$, Małgorzata Olszewska ${ }^{1}$ \& Lidia Rudnicka ${ }^{1}$
}

Erythrodermic variants of cutaneous T-cell lymphoma (CTLC) are one of the case of erythroderma. The aim of the study was to assess the value of scalp dermoscopy in differentiation between erythrodermic CTCL, psoriasis, and atopic dermatitis. A total of 76 patients were included into the study (16 patients with erythrodermic $C T C L$, 20 patients with psoriatic erythroderma, 20 with erythrodermic atopic dermatitis, and 20 healthy volunteers). The most common trichoscopic features of erythrodermic CTCL were: numerous pili torti, numerous broken hairs, white thick interfollicular bands, and patchy hyperpigmentation of the background. They were observed in $81 \%(13 / 16), 75 \%(12 / 16)$, $56 \%(9 / 16)$, and $37.5 \%(6 / 16)$ of patients with $C T C L$, respectively $(p<0.001)$. Other specific features of erythrodermic CTCL were 8 -shaped hairs $(19 \% ; 3 / 16)$ and visible anagen bulbs $(12.5 \% ; 2 / 16)$ $(p<0.05$ and $p=0.052$, respectively). The most common vascular pattern of erythrodermic CTCL was perifollicular arrangement of glomerular $(50 \% ; 8 / 16 ; p<0.001)$ or linear vessels $(31 \% ; 5 / 16 ; p<0.05)$. Follicular spicules-like scaling was pathognomonic for erythrodermic CTCL $(12 \%, 2 / 16)$ although its presence did not reach statistical significance $(p=0.052)$. In conclusion, the characteristic trichoscopic findings of erythrodermic CTCL are numerous pili torti, eight-shaped hairs, thick white interfollicular bands, color heterogeneity of the background and perifollicular arrangement of vessels.

The diagnosis of erythroderma at any age is challenging if there is no previous history of psoriasis or atopic dermatitis. Erythrodermic variants of cutaneous T-cell lymphoma (CTCL) such as Sezary Syndrome (SS) or erythrodermic mycosis fungoides are not the most common diagnoses in such cases, but establishing a proper diagnosis plays a pivotal role in disease prognosis, treatment option, and patients survival. In many cases, a definite diagnosis based on histopathology and immunohistochemistry may be difficult and clinicopathological correlation is essential for immunostaining interpretation ${ }^{1}$.

Nowadays dermoscopy is widely applied not only for preoperative evaluation of pigmented skin tumors, but also for alopecia diagnosis and is named trichoscopy $y^{2,3}$, for nail disorders-onychoscopy ${ }^{4,5}$ and inflammatory skin diseases with a name inflammoscopy ${ }^{6-8}$.

There are only few papers regarding dermoscopy of mycosis fungoides (MF). Lallas et al. ${ }^{9}$ evaluated 32 patients diagnosed with early patch stage of MF. They described fine, short, linear vessels, spermatozoa-like vascular structures and orange-yellow patchy areas. Bosseila et al. ${ }^{10}$ after analysis of 25 patients diagnosed with MF described dotted vessels as the most common vascular pattern of MF skin lesions, followed by linear pattern.

Dermoscopy of poikilodermatous MF has been first described by Xu and $\mathrm{Tan}^{11}$. It was case report of a 59 -year old patient. Dermoscopic pattern consisted of numerous polygonal structures containing white lobules divided by septa of pigmented dots and studded with fine red dots or hairpin vessels.

Ghahrmani et al. ${ }^{12}$ evaluated seven patients diagnosed with patch and plaque MF. They described the presence of regular-appearing interconnected white structureless patches encircling small fine linear vessels (fenestrated to trabeculated pattern of patchy white structureless areas). This feature was also present in $60 \%$ of patients diagnosed with folliculotropic mycosis fungoides. Additional findings included follicular erosions surrounded by dotted (40\%) and fine linear vessels (40\%), loss of terminal follicles, and comedo-like openings (60\%). 
Objective. Assuming that hair follicles can be involved in erythrodermic CTCL and folliculotropism of atypical lymphocytes should affect hair epithelium differentiation and maturation resulting in hair shafts abnormalities, the study regarding the value of scalp dermoscopy (trichoscopy) in differentiation between erythrodermic CTCL (erythrodermic MF or Sezary Syndrome), erythrodermic psoriasis, and erythrodermic atopic dermatitis was designed. To the best of our knowledge there is no study regarding trichoscopy in erythrodermic CTCL already published.

Material and methods. The analysis included 16 patients diagnosed with erythrodermic MF or SS. All of them had confirmed diagnosis based on histopathology, immunohistochemistry and in case of SS detection of monoclonal atypical circulating CD4+ lymphocytes in increased number predominating ten times over CD8+ cells ${ }^{13}$. Clonality of atypical T CD4+ was confirmed by PCR (TCR rearrangement). As a comparative group 20 patients with psoriatic erythroderma and 20 patients diagnosed with erythrodermic atopic dermatitis were stated. All patients were examined at our department between July 2016 and March 2020. As the control, 20 healthy volunteers age and sex matched to investigated groups, were examined by trichoscopy.

In each patient demographic and clinical information including sex and comorbidities was collected. In each patient, trichoscopy was performed with the use of Fotofinder digital dermoscope (at a 20- and 70-fold magnification); 10-30 pictures were taken and analyzed for each examination.

All trichoscopic images (1119 images in total) were analyzed by two independent blinded evaluators (experts in dermoscopy) for the presence of hair shaft structure abnormalities, skin surface appearance, type and arrangement of blood vessels. After evaluation, results were unblinded and compatible dermoscopic features were assigned to respective patients groups (compatibility between evaluators: 98\%).

The statistical analysis of the data was conducted using R GNU software. The differences in the incidence rate of various trichoscopic features amongst patients with erythrodermic CTCL, erythrodermic psoriasis, erythrodermic atopic dermatitis, and control group were examined with a chi-squared test with alpha correction for multiple comparisons The results were considered statistically significant with $p$-values lower than 0.05 . Sensitivity, specificity, positive and negative prognostic value, and diagnostic odds ratio were calculated for each trichoscopic feature.

The study protocol was approved by the Medical University of Warsaw Review Board for Ethics in Human Research (protocol number AWBE/90/16). All experiments were performed in accordance with relevant named guidelines and regulations. Informed consent was obtained from all participants and/or their legal guardian/s.

\section{Results}

The analysis included 16 patients with erythrodermic T-cell lymphoma [ten men and six women; mean age 56 (range 46-71)], 20 with psoriatic erythroderma [12 men, eight women; mean age 51 (range 38-67)], 20 patients diagnosed with erythrodermic atopic dermatitis [11 men and nine women; mean age 31 (range 19-51)] and 20 healthy volunteers [six men, 14 women; mean age 41 (range 26-54)].

The observed trichoscopic features included: numerous pili torti, singular pili torti, numerous broken hairs, singular broken hair, eight-shaped hairs (newly described thin, short, pigmented hair shafts, repeatedly rolled up in opposites sites), black dots, yellow dots, linear perifollicular vessels, glomerular perifollicular vessels, glomerular vessels regularly distributed or clustered, dotted vessels, arborizing vessels, glomerular vessels arranged in lines or circles localized between follicular units, white thick interfollicular bands forming net, patchy hyperpigmentation, yellow interfollicular scaling, white interfollicular scaling, follicular spicules like scaling.

Numerous pili torti (Fig. 1a,b), numerous broken hairs, white thick interfollicular bands forming net and patchy hyperpigmentation of the background were the most common and pathognomonic features for erythrodermic CTCL. They were observed in 81\% (13/16), 75\% (12/16), 56\% (9/16) and 37.5\% (6/16) of patients with cutaneous lymphomas, respectively (Table 1$)$. They were not present in patients with erythrodermic psoriasis, erythrodermic atopic dermatitis and healthy volunteers $(\mathrm{p}<0.001)$.

In two of three patients diagnosed with erythrodermic CTCL and without numerous pili torti, singular pili tort $i$ were seen and they were not observed in other study groups.

Other specific features for erythrodermic CTCL were 8-shaped hairs (Fig. 1c) and visible anagen bulbs (Fig. 1d). Although they were observed in $19 \%(3 / 16)$ and $12.5 \%(2 / 16)$ of patients, they were not present in other patients groups ( $\mathrm{p}<0.05$ and $\mathrm{p}=0.052$, respectively).

Singular broken hairs were seen in $25 \%(5 / 20)$ of patients with atopic dermatitis and $10 \%(2 / 20)$ of patients with erythrodermic psoriasis, but their presence was not statistically significant $(\mathrm{p}>0.1)$.

Black dots were found in 25\% (4/16) of patients with cutaneous lymphoma and were not seen in other study groups $(\mathrm{p}<0.05)$.

Yellow dots were observed in all patients groups; they were present in $87 \%(14 / 16)$ of erythrodermic CTCL, $19 \%(3 / 20)$ of psoriasis group, $50 \%(10 / 20)$ of atopic dermatitis group and $30 \%(6 / 20)$ of the control group. Their presence in general excludes cicatricial alopecia.

Large reddish areas were observed in $75 \%(12 / 16 ; \mathrm{p}<0.001)$ of patients with erythrodermic CTCL. Although they were also observed in $10 \%(2 / 20)$ of patients with erythrodermic atopic dermatitis and erythrodermic psoriasis, and in $5 \%(1 / 20)$ of the control group.

The most common vascular pattern of erythrodermic CTCL patients was perifollicular arrangement of glomerular $(50 \% ; 8 / 16 ; \mathrm{p}<0.001)$ or linear vessels $(31 \% ; 5 / 16 ; \mathrm{p}<0.05)$ (Fig. 2a,b). However, it was observed also in atopic dermatitis $(10 \% ; 2 / 20$ and $5 \% ; 1 / 20$, respectively).

Follicular spicules-like scaling (Fig. 2c) was rare but pathognomonic for erythrodermic CTCL $(12 \%, 2 / 16)$ although its presence did not reach statistical significance $(\mathrm{p}=0.052)$. 


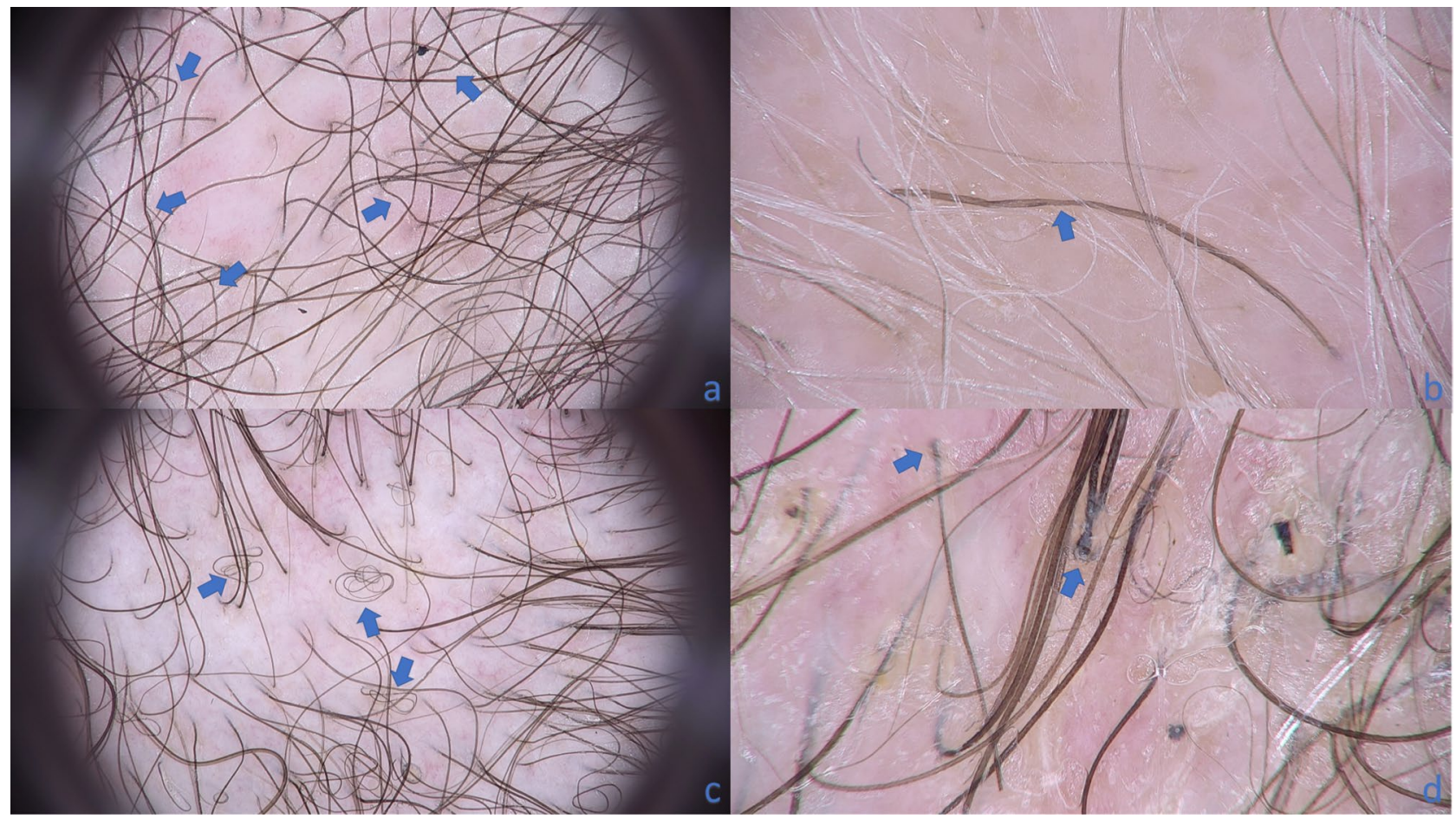

Figure 1. Hair shafts abnormalities seen in patient with erythrodermic CTCL. (a) Numerous pili torti seen in trichoscopy as bent hair shafts (blue arrow) $(\times 20)$. (b) Trichoscopy without immersion fluid and in high magnification shows short hair shaft with torsions along own axis (marked with blue arrow) $(\times 70)$. (c) Trichoscopy of erythrodermic CTCL with numerous hair shafts described as 8-shaped hairs (blue arrows) (×20). (d) Visible anagen bulbs (blue arrow) $(\times 70)$.

Sensitivity, specificity, positive and negative likelihood ratio and diagnostic odd ratio of trichoscopic criteria for erythrodermic CTCL, erythrodermic atopic dermatitis and erythrodermic psoriasis are presented in Tables 2 , 3 and 4.

Description of trichoscopic results seen in erythrodermic CTCL with its possible histopathological correlation is presented in details in Table 5.

\section{Discussion}

To the best of our knowledge there are limited studies regarding trichoscopy in patients with mycosis fungoides. Four cases have been described, in which two patients were diagnosed with erythrodermic mycosis fungoides. There is no paper regarding dermoscopy or trichoscopy in Sezary Syndrome.

Slawinska et al. ${ }^{14}$ described trichoscopy of a 88 -year old female patient diagnosed with MF who presented patchy alopecia. The authors observed decreased number of pilosebaceous units, mostly single hairs, milky-white globules, yellow dots with or without centrally located black dots/broken hairs, short hairs with split end, short broken hair, pigtail appearance hair, areas where follicles were replaced by white dots and lines, white and yellow scale. Second case report of folliculotropic MF in the aspect of trichoscopy was described by Souissi et al. The authors presented the patient diagnosed with a rare variant of folliculotropic mycosis fungoides (FMF), named spiky FMF. The trichoscopic findings in this case were thick coats of keratinaceous debris around dilated openings and hair shafts ${ }^{15}$. Miteva et al. ${ }^{16}$ described two patients with alopecia universalis associated with erythrodermic mycosis fungoides. Trichoscopic features described by authors were diffuse erythema, empty follicular openings (some contained hairs) filled in with keratotic plugs or filiform spicules, black dots, and sparse broken hairs.

In presented study the majority of pathognomonic features for erythrodermic CTCL arrived from specific hair shafts changes. The most sensitive and specific features for erythrodermic CTCL were numerous pili torti (sensitivity $81 \%$; specificity $93 \%$, positive likelihood ratio 11.65 , negative likelihood ratio 0.20 , diagnostic odds ratio 57.8; $\mathrm{p}<0.001$ ) (Fig. 1a,b).

By definition of pili torti, sections of a hair shaft are flattened at irregular intervals and rotated $180^{\circ}$ around its long axis, with each twist being 0.4 to $0.9 \mathrm{~mm}$ in width ${ }^{17}$. Pili torti may be either inherited or acquired. The most common congenital defects and syndromes associated with pili torti include: Ronchese syndrome, Beare syndrome, Bjornstad syndrome, Menkes syndrome, Rapp-Hodgkin syndrome, trichodysplasia-xeroderma, trichothiodystrophy among other rarer inherited diseases and syndromes ${ }^{18-20}$. Acquired forms of pili torti may result from repetitive trauma, oral retinoid treatment, anorexia, inflammation in cicatricial alopecia, graft-vs-host disease, scleroderma and after hair transplantation ${ }^{21,22}$. In acquired pili torti, it is presumed that uneven perifollicular fibrosis causes rotational forces on the inner root sheath that distort the hair follicle inducing formation of pili torti that may easily break, leaving broken hairs or black dots ${ }^{17}$. Another, more convincing explanation of 
\begin{tabular}{|l|l|l|l|l|} 
Atopic dermatitis $(\mathrm{N}=20)$ & Control group $(\mathrm{N}=20)$ & Psoriasis $(\mathrm{N}=20)$ & CTCL $(\mathrm{N}=16)$ & p-value
\end{tabular}

Hair shaft

\begin{tabular}{|c|c|c|c|c|c|}
\hline Numerous pili torti & $0 \%(0 / 20)$ & $0 \%(0 / 20)$ & $0 \%(0 / 20)$ & $81 \%(13 / 16)$ & $<0.001$ \\
\hline Visible anagen bulbs & $0 \%(0 / 20)$ & $0 \%(0 / 20)$ & $0 \%(0 / 20)$ & $13 \%(2 / 16)$ & 0.053 \\
\hline 8-shaped hairs & $0 \%(0 / 20)$ & $0 \%(0 / 20)$ & $0 \%(0 / 20)$ & $19 \%(3 / 16)$ & $<0.05$ \\
\hline Solitary pili torti & $0 \%(0 / 20)$ & $0 \%(0 / 20)$ & $0 \%(0 / 20)$ & $13 \%(2 / 16)$ & 0.053 \\
\hline Numerous broken hairs & $0 \%(0 / 20)$ & $0 \%(0 / 20)$ & $0 \%(0 / 20)$ & $75 \%(12 / 16)$ & $<0.001$ \\
\hline Solitary broken hairs & $25 \%(5 / 20)$ & $0 \%(0 / 20)$ & $10 \%(2 / 20)$ & $19 \%(3 / 16)$ & 0.107 \\
\hline \multicolumn{6}{|l|}{ Follicular ostia } \\
\hline Yellow dots & $50 \%(10 / 20)$ & $30 \%(6 / 20)$ & $15 \%(0 / 20)$ & $88 \%(14 / 16)$ & $<0.05$ \\
\hline Black dots & $0 \%(0 / 20)$ & $0 \%(0 / 20)$ & $0 \%(0 / 20)$ & $25 \%(4 / 16)$ & $<0.01$ \\
\hline \multicolumn{6}{|l|}{ Blood vessels } \\
\hline Linear perifollicular vessels & $5 \%(1 / 20)$ & $0 \%(0 / 20)$ & $0 \%(0 / 20)$ & $31 \%(5 / 16)$ & $<0.01$ \\
\hline $\begin{array}{l}\text { Glomerular perifollicular } \\
\text { vessels }\end{array}$ & $10 \%(2 / 20)$ & $0 \%(0 / 20)$ & $0 \%(0 / 20)$ & $50 \%(8 / 16)$ & $<0.001$ \\
\hline $\begin{array}{l}\text { Glomerular regularly distrib- } \\
\text { uted vessels }\end{array}$ & $20 \%(4 / 20)$ & $5 \%(1 / 20)$ & $100 \%(20 / 20)$ & $50 \%(8 / 16)$ & $<0.01$ \\
\hline Dotted vessels & $95 \%(19 / 20)$ & $75 \%(15 / 20)$ & $10 \%(2 / 20)$ & $25 \%(4 / 16)$ & $<0.01$ \\
\hline Arborizing vessels & $20 \%(4 / 20)$ & $50 \%(10 / 20)$ & $0 \%(0 / 20)$ & $31 \%(5 / 16)$ & $<0.01$ \\
\hline $\begin{array}{l}\text { Glomerular line arranged } \\
\text { vessels }\end{array}$ & $0 \%(0 / 20)$ & $0 \%(0 / 20)$ & $100 \%(20 / 20)$ & $13 \%(2 / 16)$ & $<0.001$ \\
\hline \multicolumn{6}{|l|}{ Background } \\
\hline $\begin{array}{l}\text { White thick interfollicular } \\
\text { bands }\end{array}$ & $0 \%(0 / 20)$ & $0 \%(0 / 20)$ & $0 \%(0 / 20)$ & $56 \%(9 / 16)$ & $<0.001$ \\
\hline Patchy hyperpigmentation & $0 \%(0 / 20)$ & $0 \%(0 / 20)$ & $0 \%(0 / 20)$ & $38 \%(6 / 16)$ & $<0.001$ \\
\hline Reddish areas & $15 \%(3 / 20)$ & $5 \%(1 / 20)$ & $10 \%(2 / 20)$ & $75 \%(12 / 16)$ & $<0.001$ \\
\hline \multicolumn{6}{|l|}{ Scale } \\
\hline Yellow interfollicular scales & $95 \%(19 / 20)$ & $0 \%(0 / 20)$ & $10 \%(2 / 20)$ & $25 \%(4 / 16)$ & $<0.001$ \\
\hline White interfollicular scales & $15 \%(3 / 20)$ & $20 \%(4 / 20)$ & $90 \%(18 / 20)$ & $88 \%(14 / 16)$ & $<0.01$ \\
\hline Follicular spicules-like scales & $0 \%(0 / 20)$ & $0 \%(0 / 20)$ & $0 \%(0 / 20)$ & $13 \%(2 / 16)$ & 0.053 \\
\hline
\end{tabular}

Table 1. Descriptive statistics among specific groups of patients: erythrodermic atopic dermatitis, control group, erythrodermic psoriasis, erythrodermic variants of cutaneous T-cell lymphoma (CTCL). Among those features only two do not perform any statistically significant differences for inter-group comparisons: visible anagen bulbs $(p=0.053)$ and single broken hairs $(p>0.1)$. For the other features further multiple comparison test was applied.

pili torti formation is unequal developing of the outer root sheath cells, leading to an irregular thickness of the outer root sheath and hair shaft formation with the subsequent twisting seen on trichoscopy ${ }^{20}$.

Acquired pili torti usually are observed in cicatricial alopecia such as lichen planopilaris, being the indication of the active lichenoid inflammatory infiltrate around upper part of the hair epithelium leading to thinning of the epithelium and induction of concentric lamellar fibrosis. Inflamed, distorted hair epithelium clenched by uneven concentric fibroplasia presents disturbed keratinization of the outer root sheath leading to the formation of the twisted hair shaft ${ }^{20,23}$. In the presented study acquired pili torti were found in majority of erythrodermic CTCL patients and were not observed in other types of erythroderma, such as psoriatic and atopic dermatitis. Their presence was not connected with the scarring process, which was excluded by the presence of yellow dots (empty follicular openings filled in with sebum and keratin). It can be hypothesized that folliculotropic inflammation without or with mucinous degeneration of the hair follicle, may induce pressure in the epithelium and pili torti formation (Fig. 3a,b,c). Therefore presence of numerous pili torti in trichoscopy of erythrodermic patient can be assumed as pathognomonic feature for erythrodermic mycosis fungoides or Sezary Syndrome, raising oncological vigilance.

Slawinska et al. ${ }^{14}$ described the presence of pigtail appearance hair, however they do not fit the classic description of this feature in the literature. The term circle hairs is used when hair has the same caliber along the hair shaft and is able to form a complete circle. Pig tail hair is thicker at the ostium, and it becomes more and more thin towards its end. Pig tail hair is assumed as the expression of thin regrowing anagen hair ${ }^{24}$. The eight-shaped hairs described in our study (Fig. 1c) are long pigmented very thin hair which are repeatedly rolled in two opposite directions forming structure resembling number 8 . They were found only in patients with erythrodermic CTCL in 19\% (3/16) and can be assumed as pathognomonic for this condition if they are numerous (sensitivity is $13 \%$ and specificity $75 \%$; $\mathrm{p}<0.05$ ). Their appearance can be also explained by the presence of folliculotropic lymphocytic infiltration.

Visible anagen bulbs were previously described in aplasia cutis congenita ${ }^{25}$, lichen planopilaris ${ }^{26}$, and erosive pustular dermatosis of the scalp ${ }^{27}$. These all conditions belong to cicatricial alopecia group. In our study visible anagen bulbs were found only in erythrodermic CTCL $(13 \% ; 2 / 16)$, although their presence has not met statistical 


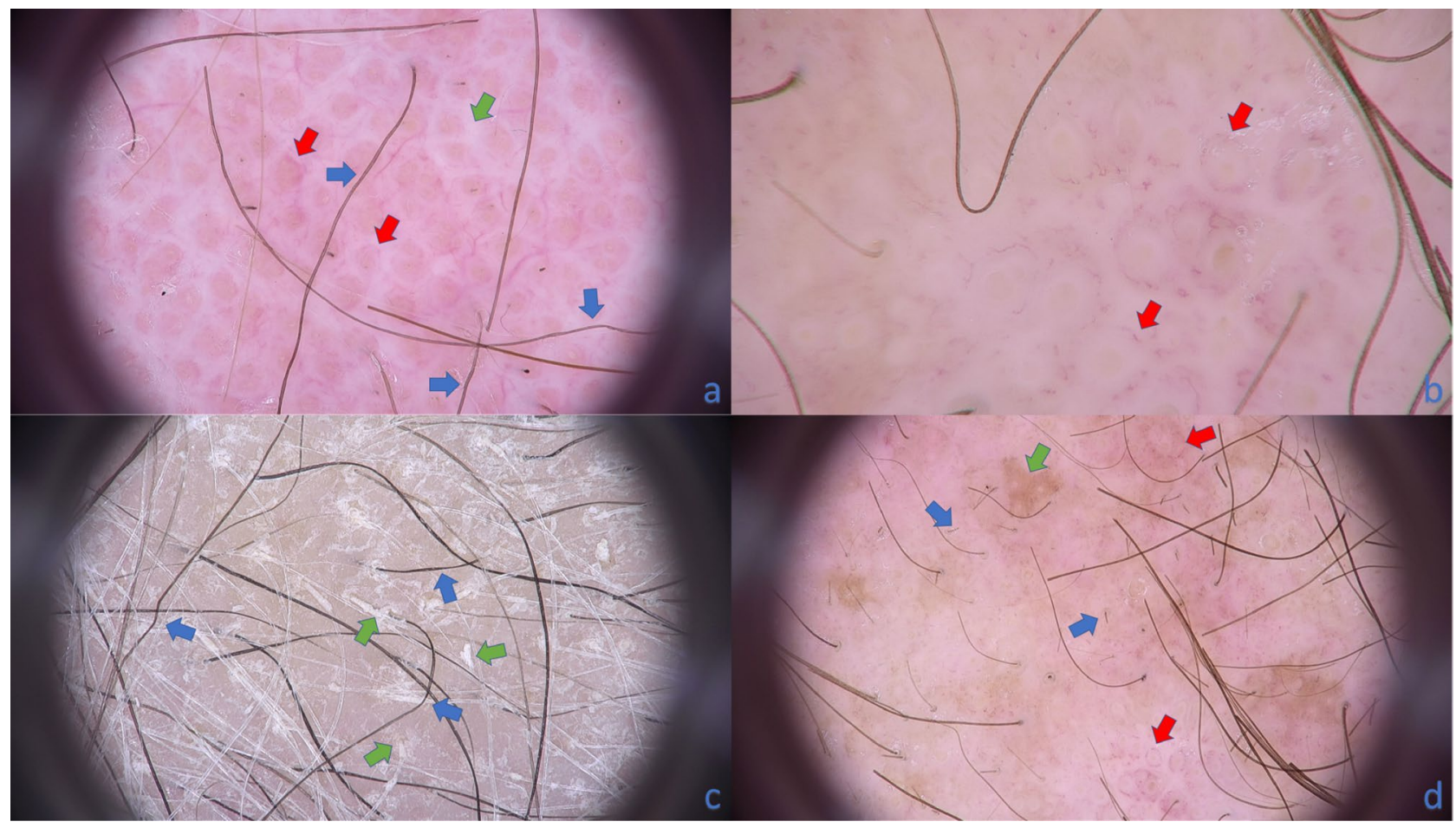

Figure 2. Trichoscopy of patient with erythrodermic CTCL. (a) The characteristic trichoscopic features visible on this image are: pili torti (blue arrows), thick white bands localized interfollicularly (green arrow) and perifollicular arrangement of linear vessels (red arrows) $(\times 20)$. (b) Vessels perifollicular arrangement can be easily recognized (red arrows). Short linear vessels are seen around yellow dots (empty follicular openings field with keratin mass and sebum $)(\times 70)$. (c) Numerous pili torti are marked with blue arrows. Additional feature seen if trichoscopy is performed without immersion fluid is follicular spicules-like scaling (green arrows) $(\times 20)$. (d) Short broken hairs are marked with blue arrows, perifollicular vessels arrangement with red arrows and patchy brownish discoloration of background with green arrow $(\times 20)$.

\begin{tabular}{|c|c|c|c|c|c|}
\hline Trichoscopic features & $\begin{array}{l}\text { Sensitivity } \\
(\%)\end{array}$ & $\begin{array}{l}\text { Specificity } \\
(\%)\end{array}$ & $\begin{array}{l}\text { Positive } \\
\text { likelihood ratio }\end{array}$ & $\begin{array}{l}\text { Negative likelihood } \\
\text { ratio }\end{array}$ & $\begin{array}{l}\text { Diagnostic } \\
\text { odds ratio }\end{array}$ \\
\hline Numerous pili torti & 81 & 93 & 11.65 & 0.20 & 57.8 \\
\hline Visible anagen bulbs & 13 & 74 & 0.48 & 1.18 & 0.4 \\
\hline 8-shaped hairs & 19 & 75 & 0.76 & 1.08 & 0.7 \\
\hline Singular pili torti & 13 & 74 & 0.48 & 1.18 & 0.4 \\
\hline Numerous broken hairs & 75 & 91 & 8.25 & 0.28 & 30.0 \\
\hline Singular broken hairs & 19 & 72 & 0.66 & 1.13 & 0.6 \\
\hline Numerous yellow dots & 88 & 93 & 12.69 & 0.13 & 94.5 \\
\hline Black dots & 25 & 77 & 1.08 & 0.98 & 1.1 \\
\hline Linear perifollicular vessels & 31 & 78 & 1.42 & 0.88 & 1.6 \\
\hline Glomerular perifollicular vessels & 50 & 83 & 2.88 & 0.61 & 4.8 \\
\hline Glomerular regularly distributed vessels & 50 & 67 & 1.50 & 0.75 & 2.0 \\
\hline Dotted vessels & 25 & 61 & 0.65 & 1.22 & 0.5 \\
\hline Arborizing vessels & 31 & 77 & 1.34 & 0.90 & 1.5 \\
\hline Glomerular line arranged vessels & 13 & 59 & 0.30 & 1.49 & 0.2 \\
\hline White thick interfollicular bands & 56 & 85 & 3.78 & 0.51 & 7.3 \\
\hline Patchy hyperpigmentation & 38 & 80 & 1.88 & 0.78 & 2.4 \\
\hline Reddish areas & 75 & 90 & 7.31 & 0.28 & 26.3 \\
\hline Yellow interfollicular scales & 25 & 61 & 0.65 & 1.22 & 0.5 \\
\hline White interfollicular scales & 88 & 90 & 9.19 & 0.14 & 66.5 \\
\hline Follicular spicules-like scales & 13 & 74 & 0.48 & 1.18 & 0.4 \\
\hline
\end{tabular}

Table 2. Sensitivity, specificity, positive and negative likelihood ratio and diagnostic odd ratio of trichoscopic criteria for erythrodermic cutaneous T-cell lymphoma vs erythrodermic psoriasis and erythrodermic atopic dermatitis. 


\begin{tabular}{|c|c|c|c|c|c|}
\hline Trichoscopic features & \begin{tabular}{l|} 
Sensitivity \\
$(\%)$
\end{tabular} & $\begin{array}{l}\text { Specificity } \\
(\%)\end{array}$ & $\begin{array}{l}\text { Positive likelihood } \\
\text { ratio }\end{array}$ & $\begin{array}{l}\text { Negative likelihood } \\
\text { ratio }\end{array}$ & $\begin{array}{l}\text { Diagnostic } \\
\text { odds ratio }\end{array}$ \\
\hline Numerous pili torti & 0 & 64 & 0.00 & 1.57 & 0.00 \\
\hline Visible anagen bulbs & 0 & 94 & 0.00 & 1.06 & 0.00 \\
\hline 8-shaped hairs & 0 & 92 & 0.00 & 1.09 & 0.00 \\
\hline Singular pili torti & 0 & 94 & 0.00 & 1.06 & 0.00 \\
\hline Numerous broken hairs & 0 & 67 & 0.00 & 1.50 & 0.00 \\
\hline Singular broken hairs & 25 & 86 & 1.80 & 0.87 & 2.07 \\
\hline Numerous yellow dots & 50 & 53 & 1.06 & 0.95 & 1.12 \\
\hline Black dots & 0 & 89 & 0.00 & 1.13 & 0.00 \\
\hline Linear perifollicular vessels & 5 & 86 & 0.36 & 1.10 & 0.33 \\
\hline Glomerular perifollicular vessels & 10 & 78 & 0.45 & 1.16 & 0.39 \\
\hline Glomerular regularly distributed vessels & 20 & 22 & 0.26 & 3.60 & 0.07 \\
\hline Dotted vessels & 95 & 83 & 5.70 & 0.06 & 95.00 \\
\hline Arborizing vessels & 20 & 86 & 1.44 & 0.93 & 1.55 \\
\hline Glomerular line arranged vessels & 0 & 39 & 0.00 & 2.57 & 0.00 \\
\hline White thick interfollicular bands & 0 & 75 & 0.00 & 1.33 & 0.00 \\
\hline Patchy hyperpigmentation & 0 & 83 & 0.00 & 1.20 & 0.00 \\
\hline Reddish areas & 15 & 61 & 0.39 & 1.39 & 0.28 \\
\hline Yellow interfollicular scales & 95 & 83 & 5.70 & 0.06 & 95.0 \\
\hline White interfollicular scales & 15 & 11 & 0.17 & 7.65 & 0.02 \\
\hline Follicular spicules-like scales & 0 & 94 & 0.00 & 1.06 & 0.00 \\
\hline
\end{tabular}

Table 3. Sensitivity, specificity, positive and negative likelihood ratio and diagnostic odd ratio of trichoscopic criteria for erythrodermic atopic dermatitis vs erythrodermic psoriasis and erythrodermic cutaneous T-cell lymphoma.

\begin{tabular}{|c|c|c|c|c|c|}
\hline Trichoscopic features & $\begin{array}{l}\text { Sensitivity } \\
(\%)\end{array}$ & \begin{tabular}{|l|} 
Specificity \\
$(\%)$
\end{tabular} & $\begin{array}{l}\text { Positive likelihood } \\
\text { ratio }\end{array}$ & $\begin{array}{l}\text { Negative likelihood } \\
\text { ratio }\end{array}$ & $\begin{array}{l}\text { Diagnostic } \\
\text { odds ratio }\end{array}$ \\
\hline Numerous pili torti & 0 & 64 & 0.00 & 1.57 & 0.00 \\
\hline Visible anagen bulbs & 0 & 94 & 0.00 & 1.06 & 0.00 \\
\hline 8-shaped hairs & 0 & 92 & 0.00 & 1.09 & 0.00 \\
\hline Singular pili torti & 0 & 94 & 0.00 & 1.06 & 0.00 \\
\hline Numerous broken hairs & 0 & 67 & 0.00 & 1.50 & 0.00 \\
\hline Singular broken hairs & 10 & 78 & 0.45 & 1.16 & 0.39 \\
\hline Numerous yellow dots & 15 & 33 & 0.23 & 2.55 & 0.09 \\
\hline Black dots & 0 & 89 & 0.00 & 1.13 & 0.00 \\
\hline Linear perifollicular vessels & 0 & 83 & 0.00 & 1.20 & 0.00 \\
\hline Glomerular perifollicular vessels & 0 & 72 & 0.00 & 1.38 & 0.00 \\
\hline Glomerular regularly distributed vessels & 100 & 67 & 3.00 & 0.00 & NA \\
\hline Dotted vessels & 10 & 36 & 0.16 & 2.47 & 0.06 \\
\hline Arborizing vessels & 0 & 75 & 0.00 & 1.33 & 0.00 \\
\hline Glomerular line arranged vessels & 100 & 94 & 18.0 & 0.00 & NA \\
\hline White thick interfollicular bands & 0 & 75 & 0.00 & 1.33 & 0.00 \\
\hline Patchy hyperpigmentation & 0 & 83 & 0.00 & 1.20 & 0.00 \\
\hline Reddish areas & 10 & 58 & 0.24 & 1.54 & 0.16 \\
\hline Yellow interfollicular scales & 10 & 36 & 0.16 & 2.49 & 0.06 \\
\hline White interfollicular scales & 90 & 53 & 1.91 & 0.19 & 10.06 \\
\hline Follicular spicules-like scales & 0 & 94 & 0.00 & 1.06 & 0.00 \\
\hline
\end{tabular}

Table 4. Sensitivity, specificity, positive and negative likelihood ratio and diagnostic odd ratio of trichoscopic criteria for erythrodermic psoriasis vs erythrodermic atopic dermatitis and erythrodermic cutaneous T-cell lymphoma. 


\begin{tabular}{|c|c|c|}
\hline Trichoscopic features & Description & Possible histopathological correlation \\
\hline Pili torti & Twisted dystrophic hair shafts & $\begin{array}{l}\text { Folliculotropic inflammation without or with mucinous } \\
\text { degeneration of the hair follicle induces pressure in the } \\
\text { epithelium affecting hair shaft formation }\end{array}$ \\
\hline Broken hairs & $\begin{array}{l}\text { Short hairs with irregular distal ends; in CTCL they are the } \\
\text { result of the breakage of pili torti }\end{array}$ & $\begin{array}{l}\text { Folliculotropic inflammation without or with mucinous } \\
\text { degeneration of the hair follicle induces pressure in the } \\
\text { epithelium and influences hair shaft strength }\end{array}$ \\
\hline Black dots & $\begin{array}{l}\text { Residues of pigmented hairs broken or destroyed at scalp } \\
\text { level; in CTCL they are the result of the breakage of pili } \\
\text { torti }\end{array}$ & $\begin{array}{l}\text { Folliculotropic inflammation without or with mucinous } \\
\text { degeneration of the hair follicle induce pressure in the } \\
\text { epithelium and influences hair shaft strength }\end{array}$ \\
\hline Numerous yellow dots & Empty follicular openings filled with sebum and keratin & $\begin{array}{l}\text { Indication of non-cicatricial alopecia caused by follicu- } \\
\text { lotropic inflammation suppresing hair epithelium proper } \\
\text { function }\end{array}$ \\
\hline 8-shaped hairs & $\begin{array}{l}\text { Long, pigmented, very thin hairs which are repeatedly } \\
\text { rolled in two opposite directions forming structure resem- } \\
\text { bling number } 8\end{array}$ & $\begin{array}{l}\text { Folliculotropic inflammation without or with mucinous } \\
\text { degeneration of the hair follicle induces pressure in the } \\
\text { epithelium and results in hair thinning }\end{array}$ \\
\hline Visible anagen bulbs & $\begin{array}{l}\text { Rectangular and dark pigmented hair bulbs, which are seen } \\
\text { on scalp surface }\end{array}$ & $\begin{array}{l}\text { Can be the result of elevation of the root of the anagen bulb } \\
\text { induced by expanding upwards folliculotropic infiltration }\end{array}$ \\
\hline Big, reddish areas & Red, patchy background color sized of a few follicular units & $\begin{array}{l}\text { Intra- and perifollicular inflammatory infiltrate from the } \\
\text { bulb to the infundibulum }\end{array}$ \\
\hline Patchy hyperpigmentation of the background & $\begin{array}{l}\text { Brownish patchy background color sized of a few follicular } \\
\text { units }\end{array}$ & $\begin{array}{l}\text { Lichenoid infiltrate of the epidermis or upper part of hair } \\
\text { epithelia with keratinocytes damage and pigment release }\end{array}$ \\
\hline Thick white bands localized interfollicularly & $\begin{array}{l}\text { Whitish background color seen as thick bands between } \\
\text { follicular units }\end{array}$ & $\begin{array}{l}\text { They correspond probably to the pushed aside and upwards } \\
\text { collagen fibers by surrounding inflammatory infiltrate, } \\
\text { mucin deposits and hair epithelium degeneration }\end{array}$ \\
\hline Perifollicular arrangement of glomerular or linear vessels & $\begin{array}{l}\text { Glomerular or linear vessels localized around follicular } \\
\text { units }\end{array}$ & $\begin{array}{l}\text { Heavy perifollicular lymphocytic infiltrate pushes up and } \\
\text { flatten superficial vascular plexus to form glomerular and } \\
\text { linear perifollicular arrangement }\end{array}$ \\
\hline Follicular spicules-like scales & $\begin{array}{l}\text { Triangular in shape keratotic structures emerging from } \\
\text { follicular orifices }\end{array}$ & $\begin{array}{l}\text { Perifollicular inflammation and lymphocyte epidermo- } \\
\text { tropism affect keratinocyte maturation and desquamation } \\
\text { leading to spicules formation }\end{array}$ \\
\hline
\end{tabular}

Table 5. Description of trichoscopic findings in erythrodermic cutaneous T-cell lymphoma (CTCL) with histopathological correlation.

significance $(p=0.052)$. Visible anagen bulb in CTCL can be the result of elevation of the root of the anagen bulb induced by expanding upwards perifollicular and folliculotropic infiltration (Fig. 1d).

Broken hairs and black dots are the result of the breakage of pili torti. In our study numerous broken hairs were found in $75 \%(12 / 16)$ of CTCL patients and were not observed in other groups $(\mathrm{p}<0.001)$ (Fig. $2 \mathrm{~d})$.

The background color seen in trichoscopy of erythrodermic CTCL patients was heterogenous. Big, reddish areas were observed in $75 \%(12 / 16)$ of those patients although they were also present in $15 \%$ of patients with erythrodermic atopic dermatitis and in one healthy individual. Patchy brownish background discoloration was observed only in patients with erythrodermic CTCL (38\%; 6/16; p <0.001) (Fig. 2d).

In $56 \%(9 / 16)$ of CTLC patients trichoscopy revealed thick white bands localized interfollicularly (Fig. 2a). They correspond most probably to the pushed aside and upwards collagen fibers induced by inflammatory infiltrate, mucin deposits, and degeneration of hair epithelium. This feature was not observed in other examined groups in presented study. Thick white bands may be trichoscopic equivalent of regularly-appearing interconnected white structureless patches encircling small fine linear vessels found in dermoscopy of MF in study of Ghrahramani et al. ${ }^{12}$. The difference may be derived by arrangement of hair follicles on glabrous skin (small vellus follicles which are densely placed) and scalp skin (bigger follicles producing terminal hair shafts which are localized in follicular units).

In previous reports vascular pattern found in patients with mycosis fungoides were fine, short, linear vessels, spermatozoa-like vascular structures and dotted vessels ${ }^{9-12}$.

Our study shows that in scalp examination of erythrodermic CTCL most pathognomonic pattern is perifollicular arrangement of glomerular or linear vessels (Fig. 2a,b) although it was not observed in 5 out of 16 patients and was present in 3 out of 20 patients diagnosed with erythrodermic atopic dermatitis. To the best of our knowledge it is first description of this particular vascular pattern.

The limitation of the study is small number of patients included into analysis and further investigations are needed.

\section{Conclusions}

If numerous pili torti are found in scalp dermoscopy of patient with erythroderma, CTCL should be suspected.

The other dermoscopic features found in this cases are: eight-shaped hairs, thick white interfollicular bands, color heterogeneity of the background (large reddish areas, patchy brownish hyperpigmentation) and particular perifollicular arrangement of glomerular or linear vessels. 

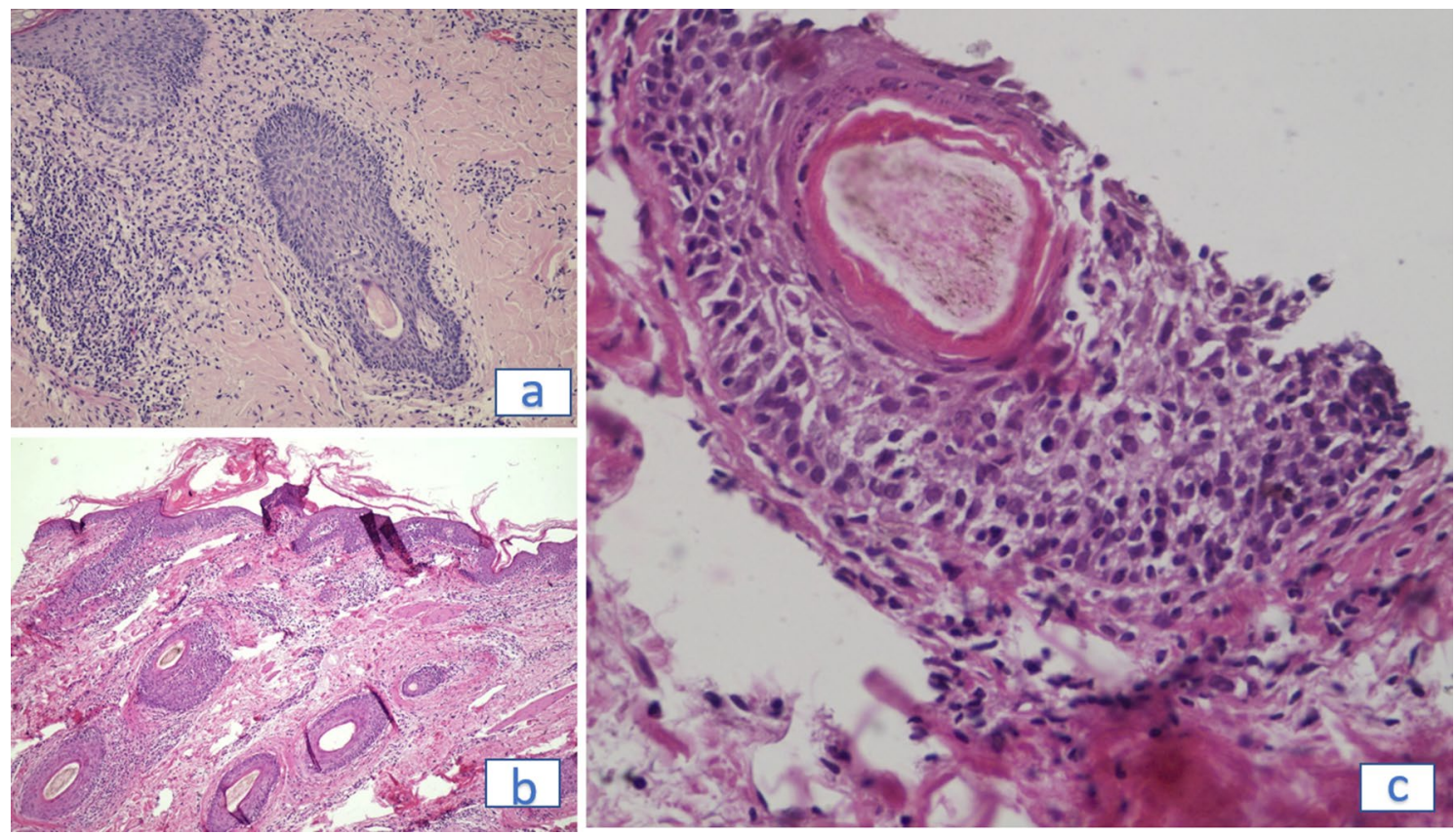

Figure 3. Scalp histopathology in erythrodermic CTCL. (a) Hair follicles with folliculotropism of atypical lymphocytes and uneven thickness of the outer root sheath (H\&E, x200). (b) On the epidermal surface the prominent follicular keratotic spicule and interfollicular scale are visible in the scalp biopsy from the patient with erythrodermic mycosis fungoides. $(\mathrm{H} \& \mathrm{E}, \times 100)$. (c) The fragment of a middle portion of the pili torti obtained in trichoscopy guided biopsy. The oval smooth shape of the hair shaft is lost. The hair epithelium is changed by lymphocytic inflammation, which leads to irregular thickness of the outer root sheath and the subsequent hair twisting. $(\mathrm{H} \& \mathrm{E}, \times 400)$.

Received: 7 August 2020; Accepted: 17 November 2020

Published online: 11 January 2021

\section{References}

1. Reddy, K. \& Bhawan, J. Histologic mimickers of mycosis fungoides: A review. J. Cutan. Pathol. 34, 519-525 (2007).

2. Rudnicka, L., Olszewska, M., Rakowska, A., Kowalska-Oledzka, E. \& Slowinska, M. Trichoscopy: A new method for diagnosing hair loss. J. Drugs Dermatol. 7, 651-654 (2008).

3. Pirmez, R. \& Tosti, A. Trichoscopy tips. Dermatol. Clin. 36, 413-420 (2018).

4. Piraccini, B. M., Balestri, R., Starace, M. \& Rech, G. Nail digital dermoscopy (onychoscopy) in the diagnosis of onychomycosis. J. Eur. Acad. Dermatol. Venereol. 27, 509-513 (2013).

5. Piraccini, B. M., Alessandrini, A. \& Starace, M. Onychoscopy: Dermoscopy of the nails. Dermatol. Clin. 36, 431-438 (2018).

6. Errichetti, E. Dermoscopy of inflammatory dermatoses (inflammoscopy): An up-to-date overview. Dermatol. Pract. Concept. 9, 169-180 (2019).

7. Blum A. et al. Inflammoscopy: Dermatoscopy for inflammatory, infiltrating and infectious dermatoses : Indication and standardization of dermatoscopic terminology. Hautarzt. (2020).

8. Errichetti, E., Lallas, A., Apalla, Z., Di Stefani, A. \& Stinco, G. Dermoscopy of granuloma annulare: A clinical and histological correlation study. Dermatology 233, 74-79 (2017).

9. Lallas, A. et al. Dermoscopy of early stage mycosis fungoides. J. Eur. Acad. Dermatol. Venereol. 27, 617-621 (2013).

10. Bosseila M., Sayed Sayed K., El-Din Sayed S. S. \& Abd El Monaem N.A. Evaluation of angiogenesis in early mycosis fungoides patients: Dermoscopic and immunohistochemical study. Dermatology. 231, 82-86 (2015).

11. Xu, P. \& Tan, C. Dermoscopy of poikilodermatous mycosis fungoides (MF). J. Am. Acad. Dermatol. 74, e45-e47 (2016).

12. Ghahramani, G. K., Goetz, K. E. \& Liu, V. Dermoscopic characterization of cutaneous lymphomas: A pilot survey. Int. J. Dermatol. 57, 339-343 (2018).

13. Olsen, E. A. et al. Clinical end points and response criteria in mycosis fungoides and Sezary syndrome: A consensus statement of the International Society for Cutaneous Lymphomas, the United States Cutaneous Lymphoma Consortium, and the Cutaneous Lymphoma Task Force of the European Organisation for Research and Treatment of Cancer. J. Clin. Oncol. 29, 2598-2607 (2011).

14. Slawinska, M., Sobjanek, M., Olszewska, B., Nowicki, R. \& Sokolowska-Wojdylo, M. Trichoscopic spectrum of folliculotropic mycosis fungoides. J. Eur. Acad. Dermatol. Venereol. 32, e107-e108 (2018).

15. Souissi, A. et al. Spiky follicular mycosis fungoides: A trichoscopic feature. J. Eur. Acad. Dermatol. Venereol. 33, e252-e253 (2019).

16. Miteva, M. et al. Alopecia universalis associated with cutaneous T cell lymphoma. Dermatology 229, 65-69 (2014).

17. Mirmirani, P., Samimi, S. S. \& Mostow, E. Pili torti: Clinical findings, associated disorders, and new insights into mechanisms of hair twisting. Cutis 84, 143-147 (2009).

18. Richards, K. A. \& Mancini, A. J. Three members of a family with pili torti and sensorineural hearing loss: The Bjornstad syndrome. J. Am. Acad. Dermatol. 46, 301-303 (2002).

19. Selvaag, E. Pili torti and sensorineural hearing loss. A follow-up of Bjørnstad's original patients and a review of the literature. Eur. J. Dermatol. 10, 91-7 (2000).

20. Evans, J. B., Hastings, J. G. \& Kaffenberger, B. H. Acquired Pili Torti. JAMA Dermatol. 155, 488 (2019).

21. Hays, S. B. \& Camisa, C. Acquired pili torti in two patients treated with synthetic retinoids. Cutis 35, 466-468 (1985). 
22. Sakamoto, F., Ito, M. \& Saito, R. Ultrastructural study of acquired pili torti-like hair defects accompanying pseudopelade. J. Dermatol. 29, 197-201 (2002).

23. Yang, J. J., Cade, K. V., Rezende, F. C., Pereira, J. M. \& Pegas, J. R. Clinical presentation of pili torti-Case report. An. Bras. Dermatol. 90, 29-31 (2015).

24. Rossi, A. et al. Monitoring chemotherapy-induced alopecia with trichoscopy. J. Cosmet. Dermatol. 18, 575-580 (2019).

25. Rakowska, A. et al. Trichoscopy of focal alopecia in children-New trichoscopic findings: Hair bulbs arranged radially along hairbearing margins in aplasia cutis congenita. Skin Appendage Disord. 2, 1-6 (2016).

26. Rakowska, A. et al. Trichoscopy of cicatricial alopecia. J. Drugs Dermatol. 11, 753-758 (2012).

27. Starace M. et al. Erosive pustular dermatosis of the scalp: A multicentre study. J. Eur. Acad. Dermatol. Venereol. (2020).

\section{Author contributions}

Conceptualization, A.R., M.J. ,L.R., J.C.; methodology, A.R., M.S.. P.G-M.; investigation, A.R., M.J., M.K., O.WH., P.G-M., J.C.; data curation, M.K., O.W-H., A.W-B.; writing-original draft preparation, A.R., M.J.; writingreview and editing, A.W-B., M.S., M.O.; supervision, A.R, L.R.; project administration, A.R., M.O.

\section{Competing interests}

The authors declare no competing interests.

\section{Additional information}

Correspondence and requests for materials should be addressed to A.R.

Reprints and permissions information is available at www.nature.com/reprints.

Publisher's note Springer Nature remains neutral with regard to jurisdictional claims in published maps and institutional affiliations.

(c) (i) Open Access This article is licensed under a Creative Commons Attribution 4.0 International License, which permits use, sharing, adaptation, distribution and reproduction in any medium or format, as long as you give appropriate credit to the original author(s) and the source, provide a link to the Creative Commons licence, and indicate if changes were made. The images or other third party material in this article are included in the article's Creative Commons licence, unless indicated otherwise in a credit line to the material. If material is not included in the article's Creative Commons licence and your intended use is not permitted by statutory regulation or exceeds the permitted use, you will need to obtain permission directly from the copyright holder. To view a copy of this licence, visit http://creativecommons.org/licenses/by/4.0/.

(C) The Author(s) 2021 